\title{
Do we need teachers as designers of technology enhanced learning?
}

\author{
Paul A. Kirschner
}

Received: 13 January 2015/Accepted: 22 January 2015/Published online: 11 February 2015

(C) The Author(s) 2015. This article is published with open access at Springerlink.com

\begin{abstract}
In this special issue, five teams of researchers discuss different aspects of the teacher as designer of technology enhanced learning situations. This final contribution critically discusses if and how teachers as designers of technology enhanced learning might (not) be feasible or even desirable. The premise underlying this critical view is that technology enhanced learning should not be seen as 'special' in comparison to other forms of learning in the teacher's arsenal. Both practicing professionals and institutions for teacher education must understand and embrace the role of design in professional competencies if technology enhanced learning is ever to be fully integrated into teaching and learning processes.
\end{abstract}

Keywords Competencies $\cdot$ Technology enhanced learning $\cdot$ Teachers $\cdot$ Design

The stated purpose of this special issue is to contribute to the discussion of the teacher as a design professional and to "provide[s] clear and timely considerations for those aiming to investigate and/or facilitate teachers as designers of technology enhanced learning" (Kali \& McKenney 2012). In line with this, I will try to make a critical yet constructive contribution to this discussion. First, I will place a few critical notes on the theme itself, namely teachers as designers of technology enhanced learning with respect to teacher competences and the ecology of education as a whole. Having done this, I will place a few critical remarks on the papers themselves. After a short discussion on what is needed for good learning, not only technology enhanced learning, I will conclude with recommendations for future work on this area, based on implications of my various considerations.

P. A. Kirschner $(\bowtie)$

Welten Institute - Research Centre for Learning, Teaching and Technology, Open University of the Netherlands, Valkenburgerweg 177, 6419AT Heerlen, The Netherlands

e-mail: paul.kirschner@ou.nl 


\section{The premise}

\section{Teacher competences}

In an article on what the pedagogical benchmarks for information and communication technologies (ICTs) in teacher education could/should be (Kirschner \& Davis 2003), Niki Davis and I wrote that, as long as institutions for teacher education see the computer or ICT as an addition to teacher training and not as something fundamental to it, the computer would never become an integral well-used part of the teaching/learning process. We wrote that, by analogy, teacher training/education institutions do not require their students to take courses on teacher aided, textbook aided or whiteboard aided instruction/learning. For the teacher, textbook and whiteboard - and their respective derivatives-are all seen as normal tools that are used in the teaching/learning process. Naturally, one needs to learn about the many different ways of teaching and of the different ways of integrating the textbook into the education process, but these aspects are almost never found in a separate course. Teacher education institutions, however, have given and continue to give teachersin-training courses that are specifically related to how they can and should use the computer and/or ICT in general in their teaching. This special issue also raises similar questions: is technology enhanced learning (TEL) something special that the teachers must design? Or is it just a subset of what 'normal' teachers should do- or at least be able to do - as the 'primary' designer of the learner's learning experience? In other words, is TEL as a distinct subcategory of learning? Should we view TEL design as a distinct subcategory of learning design? And would accepting positive answers to these questions facilitate good education and good educational design?

I consider these questions in light of teacher competencies. Van Merriënboer and Kirschner (2012) define a competency as a "combination of complex cognitive and higherorder skills, highly integrated knowledge structures, interpersonal and social skills, and attitudes and values" (p. 2). Many professionals, be they academic or vocational, have five basic competencies, which are often, though not always, used in cyclical sequence. Globally speaking, the five competences are: gathering necessary background/situational information; analyzing that information and arriving at a diagnosis for/decision as to a course of action; determining exactly what needs to be done/what steps need to be taken; carrying out the chosen actions; and evaluating whether the result of the actions was what was hoped for or expected; and if not, entering this cycle again (see Fig. 1).

"Acquired competencies can be applied in a variety of situations (transfer) and over an unlimited time span (lifelong learning)" (van Merriënboer \& Kirschner, 2012, p. 287). Important here are two aspects, namely that they are higher order and that they span long periods of time. Take a doctor as an example. A doctor needs to be able to: take a medical history (i.e., an anamnesis) of the patient; formulate a diagnosis; determine a course of action or therapy; often carry out that therapy; and finally evaluate the results of the chosen course of action to determine whether the expected results were achieved; and if not, to then enter the cycle again. The CanMEDS Physician Competency Framework (Frank et al. 2005 , p. 1) concurs, though in somewhat different words, namely:

Physicians possess a defined body of knowledge, clinical skills, procedural skills and professional attitudes, which are directed to effective patient-centered care. They apply these competencies to collect and interpret information, make appropriate clinical decisions, and carry out diagnostic and therapeutic interventions. They do so within the boundaries of their discipline, personal expertise, the healthcare setting 
Fig. 1 Competences of many professionals

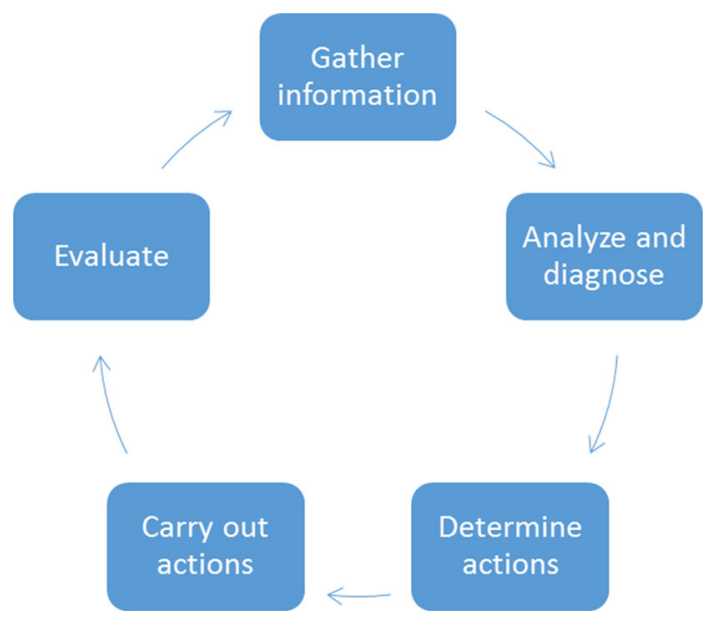

and the patient's preferences and context. Their care is characterized by up-to-date, ethical, and resource-efficient clinical practice as well as with effective communication in partnership with patients, other health care providers and the community.

These skills are all higher order skills and basically were no different 50 years ago than they are now. The major difference between 2015 and 1965, and possibly in 2065 if doctors still exist, lies in other things, namely: the knowledge that the doctor uses (e.g., 50 years ago certain diseases therapies and drugs did not exist and in fifty years this will also be the case); the techniques and her/his skills with the tools and tests available (i.e., 50 years ago doctors had to rely on X-ray images, now there is computer tomographic scanning and magnetic resonance imaging and who knows what there will be in 50 years from now); and even the social skills and attitudes necessary to be a professional (e.g., 50 years ago the doctor was an almost infallible authority to whom the patient blindly acquiesced while now the doctor is more of a second opinion [Internet being the first] with a highly vocal and empowered patient). In other words, the basic competences do not really change, but rather the enabling/underlying knowledge, skills, and attitudes do.

This is true not only of the doctor, but also for most professionals such as the lawyer, the industrial designer, etcetera. In other words, the teacher as a professional, and specifically as a professional designer of education, needs to have those same five competencies. Here too, those competences were the same 50 years ago as they are now. In light of Fig. 1, these are: gathering information about the learners (now often available in student portfolios); diagnosing/determining what is best for the learners; determining an effective and/ or efficient course of instruction; teaching/carrying out the instruction; evaluating whether that which was intended was actually achieved. What is very different in 2015 is the set of teacher knowledge, skills and attitudes. The teacher's knowledge base today includes a wealth of new and/or different domain specific knowledge, pedagogic knowledge and pedagogic content knowledge that is increasingly evidence informed. The teacher's arsenal of skills now includes new pedagogical techniques and mastery of newly available technologies. And attitudes of society, learners, parents/guardians are changing, even concerning the role and function of knowledge, learning and even formal education. From this perspective, the design of TEL is not a new competence that needs to be acquired, but is rather the twenty first century equivalent of twentieth century phenomena. The AECT 
(www.aect.org), for example, is not an association of/for educational computing as many think, but rather an association of/for educational communication and communication technologies. When it began in 1923, it was actually the National Education Association's Department of Visual Instruction and dealt with instructional design using the technologies available then (i.e., primarily audio-visual technologies such as films, film strips, opaque projectors, audio recorders, etc.). In 1969-1970 it became Association for Educational Communications and Technology reflecting their paradigm shift from an audiovisual orientation to a systems approach orientation. With this in mind, if one looks at teaching as a profession based upon a "combination of complex cognitive and higher-order skills, highly integrated knowledge structures, interpersonal and social skills, and attitudes and values" (Van Merriënboer \& Kirschner), the TEL distinction need not be made. Teachers need to receive training in how to apply what they have learnt "in a variety of situations (transfer) and over an unlimited time span (lifelong learning)". TEL is simply the newest tool on the horizon.

Finally, given that teacher education is considered academic in some settings and vocational in others, it should be noted that this is not only true for the professional who has followed academic education and/or training, but also for vocational professionals such as the travel agent, the real estate agent or the restaurant chef. ${ }^{1}$ Teachers, like other vocational professionals, make use of the tools, techniques and ingredients of the trade. Take the expert restaurant chef. (S)he, essentially, goes through the same cycle as the other professionals making use of all of the techniques, tools and ingredients that (s)he has at her/his disposal. And as is the case with other professionals, these change/vary across a life-span with respect to all three. An expert chef does not make use of only one tool, one technique or one ingredient or even a small subset of tools, techniques and ingredients. An expert chef is able to make use of a broad pallet of all three preparing delicious, appealing and often nutritious meals for different eaters for different occasions and with different needs. And here too, the tools available now are different from those that were available 50 years ago (e.g., we now have induction ranges, microwave ovens, etc.), as is also the case for the techniques (e.g., some restaurants do molecular cooking) and even the ingredients (e.g., brocoflowers, tiger trout, tangors, Wagyu meat, quinoa, etc.). And in the education of these professionals, there is no specific course in using induction ranges or convection ovens, but rather these tools are integrated into their courses on cooking, baking, deserts, etcetera.

If one combines the above two aspects, it becomes clear that the expert teacher on the one hand is capable of determining the characteristics of the learning population or individual learner, on the basis of this diagnosing what the teaching problem is that needs to be solved, prescribing an approach to the teaching process to meet those needs, carrying out the instruction and evaluating whether the approach worked. In doing this (s)he takes the learner, the class, the parents/guardians and the rest of the environment into consideration. On the other hand, in doing this, the expert teacher (in my opinion synonymous with the teacher as designer and practitioner combined) makes use of the tools, techniques and ingredients at her/his disposal to design and implement effective, efficient and enjoyable learning experiences for the learner and effective, efficient and enjoyable teaching experiences for her-/ himself. Thus, from the viewpoint of teacher competences, there is really no need for specific attention to TEL. TEL is an artefact of the times, and is essentially the educational equivalent of part of the expert chef's arsenal of tools, techniques and ingredients. The modern day expert teacher is a top-chef who integrates different educational ingredients according to

\footnotetext{
${ }^{1}$ It needs to be noted here that the profession of teacher is not an academic profession in all countries.
} 
effective, efficient and enjoyable pedagogic/educational techniques making use of the different tools and technologies afforded at this moment. As Van den Dool and Kirschner (2003, p. 176) wrote:

Teachers need to integrate ICT competence into their core teaching competences and the educational system must integrate it into the heart of learning and teaching. What really counts at the end of the day is if teachers and learners feel that ICT tools are a 'normal' part of their competences and not an add-on, either in a positive or negative sense.

Ecology of education

Another consideration is how education can actually suffer if too much emphasis is placed upon TEL, and specifically the technology used often to the detriment of learning in general. TEL is only a subset of learning and approaches to learning; even grammatically speaking, it is learning that is technologically enhanced. Two examples can illustrate what I mean here. The first is computer supported collaborative learning (CSCL). Analogous to TEL, CSCL research emphasized first the computer and computer support (i.e., the technological aspects of the CSCL environments) and later collaboration and/or collaboration processes, often to the detriment of learning (Kirschner 2002). It should actually be learning (e.g., What type of learning do we want to achieve, enhance, facilitate), in collaboration with others (e.g., when and why do we need to collaborate and why?) aided by computers joined with each other in a network (e.g., what is the reason or rationale for using the computer and how can the computer environment facilitate the learning?). The second example is the introduction of the term 'new learning'(Simons et al. 2000). New learning was originally intended by the authors as an addition to existing learning/teaching approaches. It was meant to address the fact that, in the twenty first century, people work and learn increasingly with each other and this interaction constructs new knowledge and insights (Simons, Personal Communication). Instead, new learning became a goal unto itself spawning movements and proponents who propagated the idea that 'old learning' (i.e., all of the pedagogical techniques and approaches that we already had) should be thrown overboard and that the only way to effectively learn was through constructivist pedagogies in collaboration with others. The authors (p. 8) themselves make a plea:

Not [for] a total replacement of the old kinds of learning processes by the new learning processes. Instead a new balance between old and new learning is what we really need. This new balance can also be described as new kinds of balances between guided learning, action learning and experiential learning.

In a similarly balanced way, what we should be talking about is effective, efficient and enjoyable learning that is facilitated and/or enhanced by the technologies available to the teacher, the learner and the school. In so doing, we must remember that TEL is not new. Rather, since the 'invention' and implementation of modern printing with movable type as well as the use of the blackboard by teachers in education, we have been making use of technologies to enhance learning. In other words, good education and effective, efficient and enjoyable learning is determined by the exchanges between learners, teachers and their tools, within and in interaction with, the environment. Each of these brings affordances to the teaching and learning enterprise: 
- Learners All learners enter into a learning situation with 'baggage' including their knowledge and skills, their attitudes and dispositions (e.g., motivation, determination), their meta-cognitive knowledge and skills (e.g., self-regulation), and biological/ environmental factors that can affect the learner and learning. (i.e., their cognition and the social interactions between them).

- Teachers The quality of the education and learning depends greatly on the quality of the teacher (Hattie 2013; McKinsey \& Company 2007). Teachers are vital, not only to the quality of education but also for the success or failure of educational innovation in the classroom.

- Digital tools, virtual environments and physical spaces Twenty first century education stresses seamless and ambient integration of technologies in physical environments in the sense of Weiser's (1991) notion of ubiquitous computing. Essential are links between the design of digital tools and their affordances, physical spaces, physical and virtual environments and the services and digital information within these environments.

This is what can be called the ecology of education and as in all ecosystems, it is both a system and systemic. As a system, education is a complex whole made up of elements that work together as parts of an interconnecting network. As systemic, any change or changes made in any part of the system will affect not only that part, but rather all the rest of the system. As such, education is an integrated system, which requires an integrated systemic approach to research on and in it. Finally, though bounded and separate from its environment, the educational system is surrounded and influenced by that environment (e.g., government policy, political parties, commercial companies, controlling organs such as the educational inspectorate, teacher trade unions and student groups, national and international laws and treaties, the economy, etcetera) which influences its structure, purpose and functioning.

While research evidence suggests that involvement of teachers in the design of curricula can result in effective professional development and sustainable innovations (e.g. Pieters \& Voogt 2008), the challenges associated with teachers designing technology-enhanced learning are also serious. Teachers typically have little time, limited expertise and rarely any formal endorsement for their design efforts. They are also one of the few, if not the only, professional group that in most countries does not have their own work space or 'down time' during the day to maintain and increase the professionalism. Yet they must meet new demands placed upon them by: policy, as developments towards decentralized structures require teachers to be more involved in curriculum design (e.g. Dinham 2005); research, which shows that teacher customization of materials can enhance student learning (Gerard et al. 2010); and practice, where the mismatch between existing resources and needs of specific learners/settings requires that teachers design to improve alignment (McLoughlin 2001). Thus, if research into teachers as designers of TEL is to have ecological validity, it must be undertaken in ways that accommodate the ecology of education, attending to its systems and systemic nature.

\section{The individual contributions to this special issue}

In this section I present what I feel are the weaknesses and strengths of each of the contributions, and show how these can be directed into future research and practice focused on the profession of teaching. In the first article, (McKenney et al. 2015) present an 
ecological framework for conceptualizing teacher knowledge for TEL design inspired by three research strands found in the literature on design and designing (i.e., what they call technical, phenomenological, realistic). Their goal is both to assist researchers in their study of teacher design knowledge and guide developers and facilitators of teacher professional development programs in identifying key areas to support teacher-designers in designing TEL. Their premise is that teachers are reflective practitioners that either have or need to acquire five types of knowledge, namely of why certain things should be developed and implemented, how to develop these things and how to implement them, when to act or implement tools, techniques and ingredients, whom to consult for optimal design and/or implementation, and where-at the micro, meso and macro levels-the design will or should be implemented. While the synthesis and framework provided by McKenney et al. may be useful for assisting researchers, as I further discuss below, it may fall a little short in guiding the development of programs. There are two reasons for this. The first is that the framework only emphasizes knowing (i.e., what, why, how, when and who). While knowing with respect to design is necessary, it is nowhere near sufficient. One can compare this with the difference between procedural knowledge and application. Knowing how to do something (e.g., knowing how to pole vault) is quite different from being able to do something (e.g., being able to 'clear the bar' at 6 meters). Teachers need to go further than just knowing with respect to design as intimated by McKenney et al.; they also need to both understand the five types of epistemic knowledge at the conceptual level as well as be able to apply that understanding. The question is whether this is the case by the average teacher. According to Tucker (2011) who studied the practices of top-performing countries in PISA and then set an agenda for improving the effectiveness of teacher preparation, a number of steps need to be taken to create a "world class" teaching corps. Most important priorities should be: raising entry standards into teacher education including mastery of subject matter content, moving teacher education out of professional education institutions into research universities, insist that all teachers at all levels have a depth and breadth of mastery of the subjects they will teach at least at the bachelor level. And according to McKinsey (2007), the key is (1) getting the right people to become teachers and then (2) developing them into effective instructors. In other words, we may have a long way to go to achieve McKenney et al.'s agenda. The second reason, and one which is very much allied to the first, is that the McKenney et al. paper appears to assume-seeing their discussion of the phenomenological strand - that the teacher is a reflective practitioner (Schön 1983, 1987). However, (1) reflection requires both cognitive and affective skills in the area to be reflected on, combined with processes of self-awareness, critical analysis, synthesis and evaluation (Atkins \& Murphy 1993); and (2) teachers do not necessarily have, but rather need to develop the practice of critical reflection, otherwise "they stay trapped in unexamined judgments, interpretations, assumptions, and expectations" (Larrivee 2000, p. 293).

That said, a great strength of the McKenney et al. paper is the synthesis that they provide. The synthesis is not only thorough, but also brings together, in fresh and genuine manner, bodies of knowledge (i.e., design and design thinking, instructional design, teacher learning and professional development) that are usually discrete and discussed separately by different research communities. Van Merriënboer and Kirschner (2012) would call the usual approach compartmentalized and fragmented which is not beneficial for their application in the real world. Reshuffling these bodies of knowledge and discussing them through cross-cutting lenses can serve as a great asset for those who explore practice in each of these areas, and especially in the growing area that this special issue focuses on, which I view as teacher professionalism and teacher professionalization. Another strength 
is the ecological framework. This can serve as a well-grounded basis for further research which we need, as I noted earlier, to focus on professional competencies in addition to different types of knowledge, and practical considerations.

Cober et al. (2015) studied different aspects of ownership with respect to the teacher as participatory designer. Their premise is that teachers have unique and valuable perspectives on the role of technology in education, and that it is therefore important to engage them in a participatory design process. In two case-studies, they looked at the contributions of teachers as participatory designers and defined conditions that support teachers in those endeavors. I do have doubts about the generalizability of the results obtained from two case-studies, though they were from two countries considered by Tucker (2011) to be giants upon whose shoulders the rest of the world might stand. It is also the case that the conclusion that the teachers "played a vital role in the design process-participating in preliminary discussions to address research goals, providing input and feedback into designs-in-progress, reviewing outcomes of prior efforts, and debriefing with the team during the implementation itself" may have been expected, since this is the role that the researchers gave them. On the other hand, it is not merely role allocation that yields ownership. Commitment, a fundamental aspect of ownership, grows not through externally defined participation in a project, but also from within. Teacher commitment has been shown to significantly account for variance in the degree of curriculum use (Abrami et al. 2004), yet remains difficult to bring about. Thus, given the ownership gained by teachers who embraced the roles allocated to them, Cober et al.'s paper joins a limited but important set of studies that describe the development of teacher ownership through design (e.g. Cviko et al. 2014). This kind of work helps us understand the circumstances under which it could be reasonable to expect ownership to develop, and gives considerations for supporting the development of professional competencies, as described above.

Critical reflection on this paper also prompts questions concerning inevitable, but rarely mentioned tradeoffs necessary for teacher participation in design. That is: participatory design may yield increased ownership, but at the cost of precious time and energy that could be invested elsewhere. It may also lead to a certain blindness for problems that users encounter as the owner/designer has a vested interest in and even an emotional attachment to the product. Thus, I must ask: Is participation is a worthwhile goal in itself? Or, given that teacher involvement in curriculum design can foster its ownership (Carl 2009; Kirk and MacDonald 2001) is participation primarily a vehicle for developing ownership and understanding? Further research is required in this direction to help teachers and facilitators target participatory design efforts that-first and foremost-serve to benefit educational practice.

Finally, given the focus on participation and the authors' own previous work in this area (e.g. including contributions in 2014 special issue of Instructional Science on participatory design), and the authors' acknowledgement of the value of "involving teachers and students in the design of educational innovations (e.g., Druin 2002; Könings et al. 2011)", the student is surprisingly absent in their study. It is clear that students were considered in this study, but passively, as illustrated by comments like "teachers reflected on the students' possible responses...", "how students might experience...", and "from the perspective of the students". If the student is viewed as the end user (as I believe that (s)he should), participatory design needs to include a more direct participation/contribution of the student in the design of (technology enhanced) learning environments.

Matuk et al. (2015) explore what they call the added value of teachers' re-design of curriculum materials via small, systematic adjustments. Their stated goal is to "offer rich descriptions, rather than evaluations... [and]...not to make generalizable claims about the 
role of technology in supporting teachers' customizations, but to illustrate specific cases in which it is done" so as to "begin to recognize the roles of available technologies in their work" with the ultimate goal of informing "the design of TEL materials that best support and guide customizations that promote student learning". In the case-studies used, the authors identify four types of customizations along with three technology features that supported customization. In this small yet information-rich case study, the authors did make use of student data; however, this was not through the direct involvement of the students, but rather the teachers' interpretation of logged student data and of the experienced student problems. While a helpful step, it may not constitute the level of participatory design suggested in the article's conclusion, namely of "partnerships that promote continuous exchange between curriculum designers, science content experts, teachers, researchers, developers, and students". Also, while the case is information-rich, this also poses a substantial concern: the subjective nature of the data, its analysis and the interpretations thereof. The data were already available from the authors' "archive of data" and their analysis consisted of the authors meeting "to discuss and reflect upon the interview and observational records" and "to enrich [their] interpretations of the available data, [they] also drew connections to [their] collective years of personal experience". Despite the affordances of this case, the researchers' integral involvement in teacher use of the tool, together with the lack of independent data collection, analysis or interpretation, potentially limits the value of this study for those outside the research setting. While the generalizability of these findings may be limited, the resulting design principles for supporting teacher customization, and even more so, the challenges that Matuk et al. describe for each of these principles, do point toward important directions for future research. Specifically, questions worth studying and answering include: (a) how do we design interfaces and real-time displays that make students' logged data accessible to, and usable by teachers? (b) how can authoring tools be designed that take advantage of teachers' expertise while also respecting their time? and (c) how can technologies offload the effort involved in giving individualized guidance?

In the fourth contribution, Voogt et al. (2015) examine how participation in small design teams adapting materials functions as a form of professional development yielding learning opportunities for teachers. Their basic premise is that "teacher professional development needs to be concerned with social aspects of learning, distributed across individuals and events, and directly meaningful to teachers' practice". While I do not dispute that this is necessary, as we saw in the earlier discussion of competences, both domain-related and pedagogic aspects of learning are as important as the social aspects if not more so. Voogt et al. present an elegant empirically and theoretically informed agenda for studying teacher learning by collaborative design. A specific strength of this agenda is that it draws important connections between teacher design work and broader views on teacher learning. Since the evidences brought by Voogt et al. suggest that design work is viable for professional learning, this should prompt serious discussion of how (much) teacher design work should be part of preservice, as well as in-service, education.

Here too, I do not disagree with the authors, but have two side notes. The first is that the authors discuss collaborative design at the curriculum level (i.e., at the level of group of related courses, often in a special field of study). While this is ultimately desirable, participation of the teacher in research and design might be better served by having teachers design at the lesson or course level. Curriculum level design requires a deep understanding not only of the specific content to be taught, but also of the place of the content (i.e., its role an function) with respect to the rest of what is being taught over the course of years as well as its relationship to all other things being taught (i.e., the whole picture). This is often 
beyond the competence of the teacher who teaches a subject within a curriculum. The second note is that I would urge them to go a step further than adaptation and look at shared design and construction using open educational resources. David Wiley in a series of articles on the effects of open educational textbooks (Bliss et al. 2013; Robinson et al. 2014) had teams of teachers design and develop textbooks making use of large repositories/libraries of freely available open educational resources. Such an approach within Voogt et al.'s framework might bring teachers beyond the social aspects of learning allowing them to both broaden and deepen their domain-specific knowledge as this is extremely necessary when constructing high quality learning materials.

Finally, Svihla et al. (2015), attempt to identify a 'fingerprint pattern' of supports for teachers' designing with respect to common constructs of formal programs aimed at supporting teachers as designers of TEL and the types of learning that can support such programs. Here we again see research based on highly-directed small-scale cases that vary enormously from working within an established environment to a 16 week in-service course to a three semester non-thesis master program. The results are not surprising, seeing the constraints that the authors themselves created, namely:

In each case we created spaces for the teachers to interact with each other as designers, reflecting on and engaging in design practices, such as ideation, needs assessment, iteration, and providing an opportunity to discuss failures as a means of evaluation and improvement. These were designed to assist teachers to think expansively about what is allowable and possible in their particular schools. Their designs stemmed from real needs of their local 'clients' and as such, their design work dealt with authentic problems.

This being the case, it would be hard not to find that the practices of the teachers as designers should be modeled in their own teaching environment, that the dialogue between the teachers during the collaborative design process should be supported, that the teachers-who lack formal design education and training — need to be scaffolded in the design process, and that the eventual designs should be usable in the real world. Nevertheless, the evidences provided by Svihla et al. regarding teachers' deeper understanding and adoption of new pedagogical approaches and inclinations to adopt a teacher-as-designer professional identity, are encouraging. They also relate well to the directions I noted earlier pertaining to the competences required from professional teachers (Fig. 1).

\section{Discussion and conclusions}

While the focus, methods and conclusions in the five papers of this special issue differ, each contribution shares the stance that teacher design of TEL warrants investigation and each offers insights into the problems for teachers as designers and possible solutions to those problems. Be this as it may, the five contributions have not convinced me that TEL is different from all other innovations and/or why it should be treated as such. In other words, I still have serious questions as to the need for TEL-specific discussions of teacher design competencies. Svihla et al. give - for me - a good description of my problem. They present in their contribution a case where teachers designed and implemented inquiry units incorporating collaborative technology to support knowledge' sharing where the teachers "struggled to support their students to engage in collaborative inquiry". They noted that the teachers lacked knowledge of good methods and practices for structuring and scaffolding students' inquiry efforts. I have seen similar problems with respect to CSCL where 
collaboration needed to be 'stimulated' by requiring students to post on discussion boards, etcetera. (Kirschner et al. 2014), in discussing the collaboration principle in multimedia learning, attribute this to the fact that teachers often are not capable of designing problems that 'require' collaboration. That is, they often struggle to identify where the benefits of working together in carrying out the collaborative task are greater than the transaction costs of the students for communication and coordination while carrying out the task. In other words, it is not a question of scaffolding or supporting the collaboration (and thus the design of TEL-tools for this), but rather a question of learning how to design learning tasks that are complex enough to require collaboration.

Across the paper set, I share several observations, each pointing toward recommendations for future research. First, the results obtained are rather 'soft'. The different teams used predominantly small-scale case studies with varied methods and tools. And each of the author teams noted that generalizability was limited because the cases were small and disparate. Thus, while this issue does offer richly exemplified plausible possibilities, it does not offer solid conclusions that can be generalized to different settings. Future research on similar issues should incorporate methodological alignment across cases, and possibly also broaden study designs (e.g. experiments or surveys).

Second, in design approaches termed as 'participatory', a major participant-the learner-requires specific attention. As previously noted, effective, efficient and enjoyable learning is determined by interactions between learners, teachers and their tools, each of which is situated in and influenced by the environment. Therefore, it seems crucial that research into teachers as designers of TEL — and especially those examining participatory design processes - explicitly examine the role of the learner in design. In line with the first recommendation, methods and tools for studying learner contributions across specific contexts and projects seem needed.

Third, the special issue begins with a research framework proposed by McKenney et al. This could offer a step in the direction of developing methods and tools for shared use across contexts and projects. However, it should be noted that the framework is based on a synthesis of existing literature. As such, it may not necessarily provide a comprehensive picture of what is needed. Further work is needed to specify how different research projects could make use of the framework, and how the results obtained could support or amend it. In working to elaborate/expand upon it, specific attention should be given to broadening its scope to more completely prescribing what teachers need. In my opinion, this should include not only the knowledge teachers require, but also the skills and attitudes they need to develop. While I remain skeptical about the value of a technology-specific focus, I do believe that we need research to answer questions related to the knowledge, skills and attitudes teachers need to facilitate their five core competencies (i.e. gathering information; analyzing and diagnosing; determining actions; carrying out actions; and evaluating results).

Fourth, multiple papers, and especially that of Voogt et al. are concerned with the social aspects of design and (teacher) learning. This area, however, is of most value when studied not in isolation, but rather in connection with the quality of resources designed. Therefore, I recommend that future research (a) build more explicitly on related research in the open educational resources (much of which constitute TEL); and (b) tie more clearly into the domain-specific knowledge that is required for designing high quality resources.

Finally, I return to the title of this commentary: do we need teachers as designers of technology enhanced learning? I have endeavored to offer critical yet constructive observations concerning related to the theme of teachers as designers of TEL in general, and the studies reported in this issue in particular. Though it may sound as though I do not 
agree with much that the authors of the different articles say, this could not be further from the truth. Teachers are designers - of all learning, including TEL. Research in this area is important, but the TaD (of TEL) field is still young and needs to be more clearly placed in the broader ecology of education; that is, should not be compartmentalized as something different and fragmented in the field's approach to it. Therefore, with some amendments to the mapping of the $\mathrm{TaD}$ of TEL field, as described in the introduction by Kali \& McKenney (2012), I close this commentary with suggestions for how TaD (of TEL) work (in the current special issue and in the future) could be positioned so that it matures.

Figure 2 is an amended version of the introductory mapping. It builds on the work of this special issue (represented by the triangle, which originally included ' $\mathrm{TaD}$ of $\mathrm{Tel}$ Knowledge', 'Motives for TaD of TEL', and 'Supporting TaD of TEL') but places it in the broader context of teacher professionalism (represented by the five core competencies

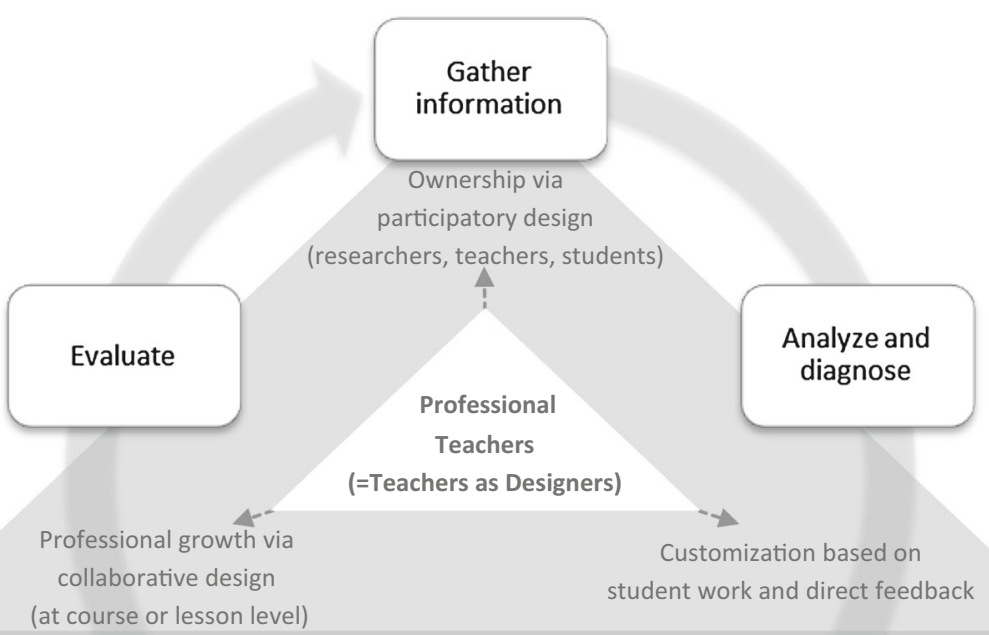

Supporting teachers to develop proficiency (Knowing, understanding and being able to...) in:

(a) domain of teaching, (b) art and science of learning and teaching, (c) science of research and design
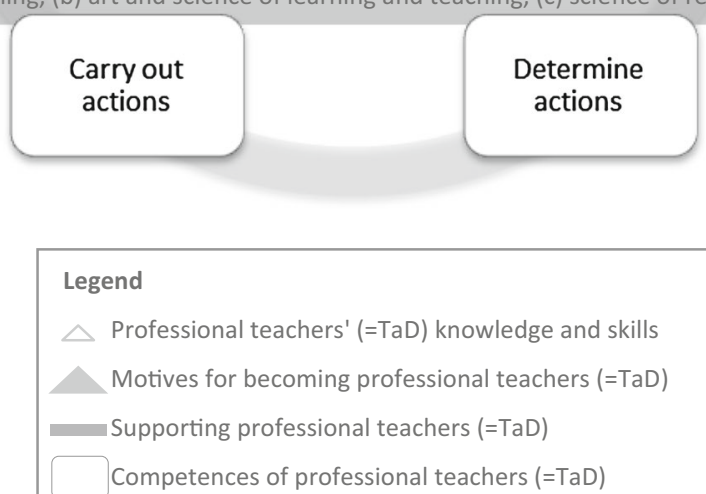

Fig. 2 Future directions for research and practice to support professional teaching (based on (Kali \& McKenney 2012)). Note that connections between competencies of professionalism and TaD motives or supports should not be implied from the figure. These should be seen as discrete layers superimposed to illustrate the various perspectives that should be taken into account in $\mathrm{TaD}$ research 
required across professions). Please note that connections between competencies of professionalism and TaD motives or supports should not be implied from this figure; these should be seen as discrete layers of a 'model' or framework superimposed on each other to illustrate the various perspectives that should be taken into account in $\mathrm{TaD}$ research). Note also that this version of the mapping emphasizes the stronger role that I suggest for students in participatory design and customization, as well as the more limited scope of artifacts to be designed by teachers (course or lesson level, rather than whole curricula).

As visualized in the support component of Fig. 2, teachers as professionals also need to be professional learners and to function as researchers into their own practices. Their initial and continuing training must equip them to learn and work as co-researchers and codesigners of the technology and tools they want and need to use. The integral development of expertise and competence on the 'shop-floor'-especially integrating the educative functions of ICT in their toolboxes-is a requirement for effective, efficient and enjoyable integration of ICT into teaching and learning. The key to this is the dynamic interaction between the respective networks, communities and actors involved in the knowledge chains in the practice of education, the training of teachers, and in research and development agencies (Van den Dool \& Kirschner 2003, p. 176).

However, achieving such dynamic interaction implies a drastic rethinking of both initial pre-service education and continuing, in-service education. As illustrated in Fig. 2, teachers need to be seen as and become accomplished at the least in three fields, namely the domain in which they teach (i.e., they must know, understand and be able to apply the subjects that they teach at the conceptual level), the art and science of learning and teaching (i.e., they must know, understand and be able to apply the different pedagogies that can be used to achieve the goals that they need to achieve), and the science of research and design. Only then will teachers be competent designers of learning, including TEL.

Open Access This article is distributed under the terms of the Creative Commons Attribution License which permits any use, distribution, and reproduction in any medium, provided the original author(s) and the source are credited.

\section{References}

Abrami, P. C., Poulsen, C., \& Chambers, B. (2004). Teacher motivation to implement an educational innovation: Factors differentiating users and non-users of cooperative learning. Educational Psychology, 24, 201-216.

Atkins, T. W., \& Murphy, K. (1993). Reflection: A review of the literature. Journal of Advanced Nursing, $18,1188-1192$.

Bliss, T. J., Hilton, J, I. I. I., Wiley, D., \& Thanos, K. (2013). The cost and quality of online open textbooks: Perceptions of community college faculty and students. First Monday, 18, 1-7.

Carl, A. (2009). Teacher empowerment through curriculum development: Theory into practice. Cape Town, South Africa: Juta.

Cober, R., Tan, E., Slotta, J., So, H-J., \& Könings, K. D. (2015). Teachers as participatory designers: Two case studies with technology-enhanced learning environments. Instructional Science, 1-26. doi:10. 1007/s11251-014-9339-0.

Cviko, A., McKenney, S. \& Voogt, J. (2014). Teachers as co-designers of technology-rich learning activities for emergent literacy. Technology, Pedagogy and Education, ISSN 1475-939X.

Dinham, S. (2005). Principal leadership for outstanding educational outcomes. Journal of Educational Administration, 43, 338-356. doi: 10.1108/09578230510605405.

Druin, A. (2002). The role of children in the design of new technology. Behaviour and Information Technology, 21(1), 1-25.

Frank, J. R., Jabbour, M., Frechette, D., Marks, M., Valk, N., \& Bourgeois, G. (Eds.). (2005). CanMEDS physician competency framework: Report of the CanMEDS phase IV working groups. Ottawa, Canada: 
The Royal College of Physicians and Surgeons of Canada. Retreived from http://www.royalcollege.ca/ portal/page/portal/rc/common/documents/canmeds/framework/the_7_canmeds_roles_e.pdf.

Gerard, L. F., Spitulnik, M., \& Linn, M. C. (2010). Teacher use of evidence to customize inquiry science instruction. Journal of Research in Science Teaching, 47, 1037-1063. doi: 10.1002/tea.20367.

Hattie, J. (2013). Visible learning and the science of how we learn. Oxford: Taylor \& Francis.

Kali, Y., \& McKenney, S. (2012). Teachers as designers of technology enhanced learning. In J. van Aalst, K. Thompson, M. J. Jacobson, \& P. Reimann (Eds.), The future of learning: Proceedings of the 10th international conference of the learning sciences (Vol. 2, pp. 582-583). Sydney: International Society of the Learning Sciences.

Kirk, D., \& MacDonald, D. (2001). Teacher voice and ownership of curriculum change. Journal of Curriculum Studies, 33, 551-567.

Kirschner, P. A. (2002). Can we support CSCL? Educational, social and technological affordances for learning. In P. Kirschner (Ed.), Three worlds of CSCL: Can we support CSCL. Inaugural address. Heerlen: Open University of the Netherlands.

Kirschner, P. A., \& Davis, N. (2003). Pedagogic benchmarks for ICT teacher education. Technology, Pedagogy and Education, 12, 127-149.

Kirschner, P. A., Kirschner, F., \& Janssen, J. (2014). The collaboration principle in multimedia learning. In R. Mayer (Ed.), The Cambridge handbook of multimedia learning (2nd ed., pp. 547-575). New York: Cambridge University Press.

Könings, K. D., Brand-Gruwel, S., \& van Merriënboer, J. J. G. (2011). Participatory instructional redesign by students and teachers in secondary education: Effects on perceptions of instruction. Instructional Science, 39, 737-762.

Larrivee, B. (2000). Transforming teaching practice: becoming the critically reflective teacher. Reflective Practice, 1, 293-307.

Matuk, C. F., Linn, M. C., \& Eylon, B. S. (2015). Technology to support teachers using evidence from student work to customize technology-enhanced inquiry units. Instructional Science, 1-29. doi:10. 1007/s11251-014-9338-1.

McKenney, S., Kali, Y., Markauskaite, L., \& Voogt, J. (2015). Teacher design knowledge for technology enhanced learning: An ecological framework for investigating assets and needs. Instructional Science, 1-22. doi:10.1007/s11251-014-9337-2.

McKinsey \& Company. (2007). How the world's best-performing school systems come out on top. Amsterdam: McKinsey.

McLoughlin, C. (2001). Inclusivity and alignment: Principles of pedagogy, task and assessment design for effective cross-cultural online learning. Distance Education, 22(1), 7-29. doi: 10.1080/01587910102 20102.

Pieters, J., \& Voogt, J. (2008). Curriculum, docent en innovative [Curriculum, teacher and innovation], research program of the department curriculum design and educational innovation. Enschede: University of Twente.

Robinson, T. J., Fischer, L., Wiley, D., \& Hilton, J, I. I. I. (2014). The impact of open textbooks on secondary science learning outcomes. Educational Researcher, 43, 341-351.

Schön, D. A. (1983). The reflective practitioner: How professionals think in action. New York: Basic Books.

Schön, D. A. (1987). Educating the reflective practitioner: Toward a new design for teaching and learning in the professions. San Francisco, CA: Jossey-Bass.

Svihla, V., Reeve, R., Sagy, O., Kali, Y. (2015). Fingerprint pattern of supports for teachers' designing of technology-enhanced learning. Instructional Science. doi:10.1007/s11251-014-9342-5.

Simons, R. J., van der Linden, J., \& Duffy, T. (2000). New learning: Three ways to learn in a new balance. In R.-J. Simons, J. Van der Linden, \& T. Duffy (Eds.), New learning (pp. 1-20). Dordrecht, the Netherlands: Wolters Kluwer.

Tucker, M. S. (2011). Standing on the shoulders of giants: An American agenda for education reform. Washington DC: National Center on Education and the Economy. Retrieved from http://www.ncee. org/wp-content/uploads/2011/05/Standing-on-the-Shoulders-of-Giants-An-American-Agenda-forEducation-Reform.pdf.

van den Dool, P., \& Kirschner, P. A. (2003). Integrating the educative functions of ICT in 'the teachers and learners toolboxes': A reflection on pedagogical benchmarks for ICT in teacher education. Technology, Pedagogy and Education, 12, 161-179.

Van Merriënboer, J. J. G., \& Kirschner, P. A. (2012). Ten steps to complex learning (2nd ed.). New York: Taylor \& Francis.

Voogt, J., Laferrière, T., Breuleux, A., Itow, R. C., Hickey, D. T., \& McKenney, S. (2015). Collaborative design as a form of professional development. Instructional Science. doi:10.1007/s11251-014-9340-7.

Weiser, M. (1991). The computer for the 21st century. Scientific American, 265(3), 94-104. 